\title{
Some major milestones and future directions
}

\author{
R. Rodney Howell, $M D$
}

It is my pleasure to review the major milestones in the brief history of the American College of Medical Genetics, and more importantly, summarize the future that the membership has planned for the College based on the focus groups during the past year.

The American College of Medical Genetics (ACMG) was formed in 1991. During its early years, the ACMG focused on the creation of a viable medical college and the support of the development of medical genetics as a clinical practice specialty. Soon after forming, the College in 1992 submitted the first CPT codes to the AMA CPT Code Committee. The first edition of the ACMG Laboratory Standards and Guidelines appeared in 1993, and the first national annual clinical genetics meeting took place in 1994.

In 1996, the College obtained full membership in the AMA House of Delegates, a goal established at the founding of the College. The laboratory AMA CPT codes were passed by the CPT Committee in the same year. During this period of time, there was an additional major focus on accumulating operating reserves for financial stability of the organization, and in 1997, we were fortunate to identify and hire our first permanent staff.

In 1998, the first edition of the Genetics in Medicine was published and in 1999, the decision was made to recruit an Executive Director of the College. Now is the time for the College to take the next bold step into a very much broader perspective.

In October of 1998 at the ACMG business meeting, the members charged the Board with creating a strategic plan for the College to address the members' most pressing needs, to articulate a plan for the College, to further the direction of the College, and to help establish the organization's identity. In response, the Board initiated a planning effort with three components: collect member input and feedback, then review the feedback and the ongoing trends, and convene a planning conference.

We have utilized a five-step approach to creating a plan for the College. The first of these steps was to create a common understanding of the College history and the current environment. The second was to understand the strengths, problems, opportunities, and threats to the College. Third was to define a picture of the American College of Medical Genetics in the future. The fourth step was to identify the major bold steps the ACMG needs to take, and finally the fifth step was for the

From the Department of Pediatrics, Unversity of Miami School of Medicine, Miumi, Florida. Presented at the Annual Clinical Genetics Meeting, Palm Springs, Marth 20 on.
ACMG to develop preliminary action plans. The entire planning effort was organized under the direction of the Board with the strong assistance and help of our nationally recognized strategic planning expert.

After the Board decision to perform the strategic planning in October of 1998, the collection of member feedback began with focus groups at the Annual Clinical Genetics Meeting in Miami, March, 1999. The Board met following the meeting and reviewed the member feedback as well as needs and trends at a July 1999 meeting. This preceded the second series of the focus groups that were held during the American Society of Human Genetics meeting in San Francisco. Finally, the planning conference held in January of 2000 in Miami organized the work of the focus groups.

The focus groups at the Annual meeting in March of 1999 were extremely effective. There were 6 focus groups each with about 15 participants. The members were self-selected to discuss billing and reimbursement, education, clinical practice guidelines, laboratory practice guidelines, professional recognition, and other issues (Table 1).

The focus groups in San Francisco during the ASHG meeting were also critical to this process. These identified key areas in which ACMG should focus:

1. Identify and provide practical information to help members create and sustain economic viability in the profession, including:

- information, procedures, and codes for billing and reimbursement;

- successful business and economic models and practice guidelines.

2. Take a large advocacy and educational role with state and federal policymakers, other medical professionals, insurance industry, and the general public:

- become the authoritative voice on medical genetic topics, standards, and guidelines;

- improve the visibility of medical genetics, its value, and its professionals and collaborate with them.

3. Improve communication with ACMG membership about:

- resources available to assist members;

- process and status of issues being addressed;

- how membership can assist.

\section{Problems and challenges}

Problems with the American College of Medical Genetics were identified. These were summarized as the presence of 
Table 1

Issues discussed

\begin{tabular}{lcc}
\hline & \multicolumn{2}{c}{ Priority to Improve } \\
\cline { 2 - 3 } & $\begin{array}{l}\text { Low } \\
(\%)\end{array}$ & $\begin{array}{c}\text { High } \\
(\%)\end{array}$ \\
\hline Billing \& reimbursement & 6 & 94 \\
Clinical practice guidelines & 8 & 92 \\
Lab. practice guidelines & 17 & 83 \\
Professional recognition & 7 & 93 \\
Education & 8 & 92 \\
Annual meetings & 16 & 84 \\
Other & 8 & 92 \\
\hline
\end{tabular}

competing organizations and lack of a clear identity; the College had been too slow and cautious; there has been a lack of permanent full-time staff; and we were a very small group, which limited our influence. However, it was also recognized that connecting as we have in the AMA and to other groups gave us a much greater voice than one might expect. The College was also recognized as being unsophisticated in working with government and having difficulty showing value of genetic services. Some of the threats identified were that the College was not unique; laboratories, hospitals, and nongeneticists are performing certain laboratory studies; and physicians do not regularly refer patients to geneticists. There are in addition competing organizations for authoritative voices and at the current time a low priority for genetic services in society, which is accompanied by low reimbursement for these services. All of these threats facing clinical medical genetics are amplified in the arena of managed care where similar problems are found by most medical groups.

\section{Strengths}

Many strengths were identified in the American College of Medical Genetics: the expertise and knowledge of the group, the presentation and planning of standards and guidelines, and the fact that the College is dealing effectively with issues that are very important to the public and government. The ties of the American College of Medical Genetics to academia and advocacy were recognized as being very important. Many great opportunities were realized during the focus groups. These focused in the areas of education, advocacy, public policy, outcomes data, and the defining of performance standards.

The Board of the American College of Medical Genetics used the findings from these focus groups to serve as a foundation for a planning conference held in Miami in January of 2000. This two-day retreat brought together over 30 people who worked extremely effectively during this time. The group included officers, directors, and nationally recognized geneticists who served as advisors. Not all participants were members of the American College of Medical Genetics. As a result of this planning conference, the Board and this group defined the elements of the vision for the College, identified key opportu- nities for the College and defined major strategies to be undertaken.

\section{Vision}

The vision for ACMG has three parts:

1. The College must have a member-driven focus that influences all ACMG activities, products, and services. The College must provide practical information for the members' success, such as CPT codes and guidelines. The College must provide member development resources including but not limited to education, re-tooling, annual meetings, and the new journal, and must embrace other specialties in ACMG membership to broaden our abilities to carry out our central goals.

2. The College must integrate genetic programs and services by partnering with other organizations, focus on the genome translation effort, and emphasize integration of genetics into mainstream medicine.

3. In order to establish advocacy and leadership, the College must exhibit leadership in educating the public about genetics, its values, its professionals, and their services. We must exhibit leadership in advocacy for public good, exhibit leadership with an authoritative voice for and of the profession.

It was important to prioritize the opportunities that were identified for the American College of Medical Genetics. These were:

1. Provide support in education for members, policymakers, insureds, and the general public.

2. Assume a large advocacy role for the public good.

3. Integrate genetics into mainstream medicine and collaborate with other medical professionals to impact public policy.

4. Develop and compile outcomes data.

5. Devise standards including performance practices in economics.

To take advantage of the opportunities at hand, The American College of Medical Genetics will adopt a five-part strategy:

1. We will focus research on genome translation initiative.

2. We will improve communication within and outside of ACMG.

3. We will aggressively expand the financial base.

4. We will actively assist members with practice viability.

5. We will identify, explore, and implement partnerships.

In the first opportunity of focusing research on the genome translation initiative, our first major objectives will be to form a consortium with industry, government, consumers, and payors to transition genetic test availability and utility to patient care, to strengthen the liaison to genome research, and to focus efforts on translating science into clinical practice.

The second of these major objectives to improve communication within and outside of the American College of Medical Genetics, our major objectives will be to: 
1. Create a new Web site and utilize more technology channels for communication and information access for both general and public members.

2. Increase American College of Medical Genetics visibility and media interaction by taking part in and creating public service announcements to market ACMG and its interests more aggressively and produce and distribute timely position papers on critical issues.

Our third objective is to aggressively expand the financial base. To achieve this, we will develop and enact a business plan and increase nondues revenue by rethinking the approach for managing and obtaining income from exhibits at meetings, efforts in continuing education grants, and the provision of courses.

Our fourth major effort will be to actively assist members with practice viability. The major objectives under this goal will be to provide support and education regarding business practices and political advocacy, the first of which will be tools to sustain and improve services, and the second, resources to sustain and improve services. The second section will be to provide support and successful educational business models for members, including best practices for billing and reimbursement and economic models for successful practices. The third section is to expand membership categories to attract professionals bordered by other specialties and the general public.

Our fifth and final major goal will be to identify, explore, and implement new partners. The major objectives here will be to create and grow relationships and partners with other medical professionals such as the AMA, the American Academy of Pediatrics, the American College of Obstetrics and Gynecology, the American Academy of Family Practice, the College of American Pathology, the American Society of Human Genetics, the National Society of Genetic Counselors, and the International Society of Nurses in Genetics. We will seek to create a working relationship within government with HCFA, NHGRI, NICHD, CDC, HRSA, MCH, HHS and ASTO; commercial organizations such as industry groups, HIAA, and insurers; and concerned public organizations such as the Alliance. We will attempt to delineate relationships between genetic organizations and increase the level of industry support for meetings. It was widely recognized that considerable infrastructure support would be required to support ACMG's strategy. The Board has planned to make extensive changes in the organizational infrastructure to:

1. Re-examine, re-define, and streamline the current committee structure relative to strategies and needs moving forward.

2. Increase member participation at business meetings.

3. Utilize the Web and newer technology as an integral part of communicating to its supporting members.

There must be considerable enhancement of the administrative infrastructure which will expand the ACMG personnel resources, the most important of which will be the recruitment and identification of an Executive Director, a Web Master, and staffing for committee projects. This will require the expansion of headquarters space.

\section{Successes}

I want to review with you some of the extraordinary successes that our young College has enjoyed in its brief history. Genetics In Medicine is a real success story. Volume 1, No. 1, was published in November of 1998, and Volume 1, No. 7, in November-December of 1999. Richard A. King, M.D., Ph.D., is the Editor-in-Chief, with editors in molecular genetics, clinical genetics, CME, biochemical genetics, clinical informatics, genetic counseling, public health and epidemiology, education, common diseases, and cytogenetics.

A big deal for a new journal has just occurred in that the ISI has agreed to index Genetics in Medicine in Science Citation Index Expanded, ISI alerting services, Current Contents/Clinical Medicine, and Biotechnology Citation Index. This index goes back to Volume 1, No.1, and we now can follow our impact factor. However, Genetics in Medicine needs you to achieve its ultimate goals. The journal needs between 120 and 150 manuscripts a year, so we can publish only the highest quality papers, and publish the journal on time. The editors have worked hard and have cut down the turnaround time and manuscript review. We go with the electronic online edition in September, with the $4^{\text {th }}$ issue of Volume 2. After extensive interviews, the journal leadership and the Board have chosen HighWire, which is the premier online journal service affiliated with Stanford University. They are recognized to be among the best in the business and much excitement surrounds this.

The College's practice guidelines have had an enormous impact. Working under a major grant from the New York State Department of Health awarded to the American College of Medical Genetics Foundation, Dr. Michael Kaback and Ms. Karen Greendale have overseen these projects with broad input from a variety of specialties throughout New York State for the production of two major practice guidelines. First of these is Genetic Susceptibility to Breast and Ovarian Cancer: Assessment, Counseling, and Testing Guidelines and the second, Evaluation of the Newborn with Single or Multiple Congenital Anomalies. These documents are widely recognized as authoritative in this area and will clearly establish the standards of practice.

The Second Edition of the Standards and Guidelines for Clinical Genetics Laboratories has been published. This work presents the standard of practice for medical genetics laboratories and is widely quoted. This was a product of the hard work of the Quality Assurance Subcommittee of the Laboratory Practice Committee.

The College has been extremely active in the current controversy over the patenting of gene sequences. The American College of Medical Genetics Position Statement on Gene Patents and Accessibility of Gene Testing published in Genetics in Medicine in July/August of 1999 has been widely quoted not only in the popular and lay press but in a variety of professional journals. The authoritative voice of a professional organization 
such as the College on an issue like patents has been widely appreciated. This position of the College also led to our ability to cosponsor a meeting in Washington in the spring of 2000 on gene patents. This important meeting involved not only leaders from the Patent and Trademark Office but leaders from the College, various genetic organizations, various commercial organizations, and a variety of legal scholars. The College has been very visible testifying about various positions during the ongoing deliberations of the Secretary's Advisory Committee on Genetic Testing. Those continue today. There has been considerable recognition of the College's role in the practice of medical genetics. A recent example of this recognition was an invitation by the White House to attend the signing of the Genetic Discrimination Bill by President Clinton. The request to cochair the meeting in Washington in March of 2000, with leaders to discuss the genetic patents and several recent requested meetings with the FDA, HRSA, HICFA, CDC, CAP, and others to discuss genetic testing are additional indications of recognition.

Progress is being made on the identification and selection of the Executive Director, the ads for the Executive Director have appeared, and already, qualified applicants have submitted material in response to the ads.

This extraordinarily successful meeting here in Palm Springs underlines the fact that the American College of Medical Genetics, although young and with many challenges, is set on a course for success in the future. This particular meeting in Palm Springs is by far the largest meeting that the College has had as far as attendance is concerned, and the quality of the papers seems to be increasing significantly. I believe having identified the opportunities that we have, the challenges that we face, and specific plans made for the future, the College will be indeed an effective advocate for the practitioner of medical genetics and an organization that will attract and represent a broad range of medical genetic professionals. We will help ensure that the public directly benefits from the vast amount of information being derived from genomic research.

\section{Acknowledgments}

I would like to thank Mr. Brook Rolter and Ms. Gerry Gurvitch for organizing and directing the strategic planning efforts. 